NASA/TM-2000-210237

\title{
Thermophysical and Thermomechanical Properties of Thermal Barrier Coating Systems
}

Dongming Zhu

Ohio Aerospace Institute, Brook Park, Ohio

Robert A. Miller

Glenn Research Center, Cleveland, Ohio

Prepared for the

24th Annual Cocoa Beach Conference and Exposition,

International Conference on Engineering Ceramics and Structures

sponsored by the American Ceramic Society

Cocoa Beach, Florida, January 23-28, 2000

National Aeronautics and

Space Administration

Glenn Research Center 
Available from

NASA Center for Aerospace Information 7121 Standard Drive

Hanover, MD 21076

Price Code: A03
National Technical Information Service 5285 Port Royal Road Springfield, VA 22100 Price Code: A03 


\title{
THERMOPHYSICAL AND THERMOMECHANICAL PROPERTIES OF THERMAL BARRIER COATING SYSTEMS
}

\author{
Dongming Zhu \\ Ohio Aerospace Institute \\ Brook Park, Ohio 44142 \\ Robert A. Miller \\ National Aeronautics and Space Administration \\ Glenn Research Center \\ Cleveland, Ohio 44135
}

\begin{abstract}
Thermal barrier coatings have been developed for advanced gas turbine and diesel engine applications to improve engine reliability and fuel efficiency. However, the issue of coating durability under high temperature cyclic conditions is still of major concern. The coating failure is closely related to thermal stresses and oxidation in the coating systems. Coating shrinkage cracking resulting from ceramic sintering and creep at high temperatures can further accelerate the coating failure process. The purpose of this paper is to address critical issues such as ceramic sintering and creep, thermal fatigue and their relevance to coating life prediction. Novel test approaches have been established to obtain critical thermophysical and thermomechanical properties of the coating systems under near-realistic temperature and stress gradients encountered in advanced engine systems. Emphasis is placed on the dynamic changes of the coating thermal conductivity and elastic modulus, fatigue and creep interactions, and resulting
\end{abstract}

An invited paper presented at the 24th Annual Cocoa Beach Conference and Exposition, International Conference on Engineering Ceramics and Structures, Cocoa Beach. Florida, January 23-28, 2000. 
failure mechanisms during the simulated engine tests. Detailed experimental and modeling results describing processes occurring in the thermal barrier coating systems provide a framework for developing strategies to manage ceramic coating architecture, microstructure and properties.

\section{INTRODUCTION}

Ceramic thermal barrier coatings (TBCs) have received increasing attention for advanced gas turbine and diesel engine applications. The advantages of using ceramic thermal barrier coatings include increased engine thrust and power density, fuel efficiency, and improved engine reliability. A typical twolayer TBC system consists of a $\mathrm{ZrO}_{2}-\mathrm{Y}_{2} \mathrm{O}_{3}$ ceramic top coat and an oxidationresistant metallic bond coat. Figure 1 shows micrographs of typical plasmasprayed and electron beam physical-vapor-deposited (EB-PVD) thermal barrier coatings.

Durability issues of thermal barrier coatings under high temperature cyclic conditions are of major concern. The coating failure modes are usually complex, depending on the coating operating conditions and coating structures. In general, the coating failure is closely related to thermal stresses in the coating systems, and oxidation of the bond coat and substrate. It has been recognized [1] that the coating failure driving force increases, whereas the resistance decreases, with time, due to many time- and temperature- dependent processes occurring in the coating systems, as shown schematically in Figure 2. As a consequence, coating life prediction models have to incorporate the dynamic thermomechanical and thermophysical property information, along with appropriate failure mechanisms observed under near-realistic temperature and stress conditions. 

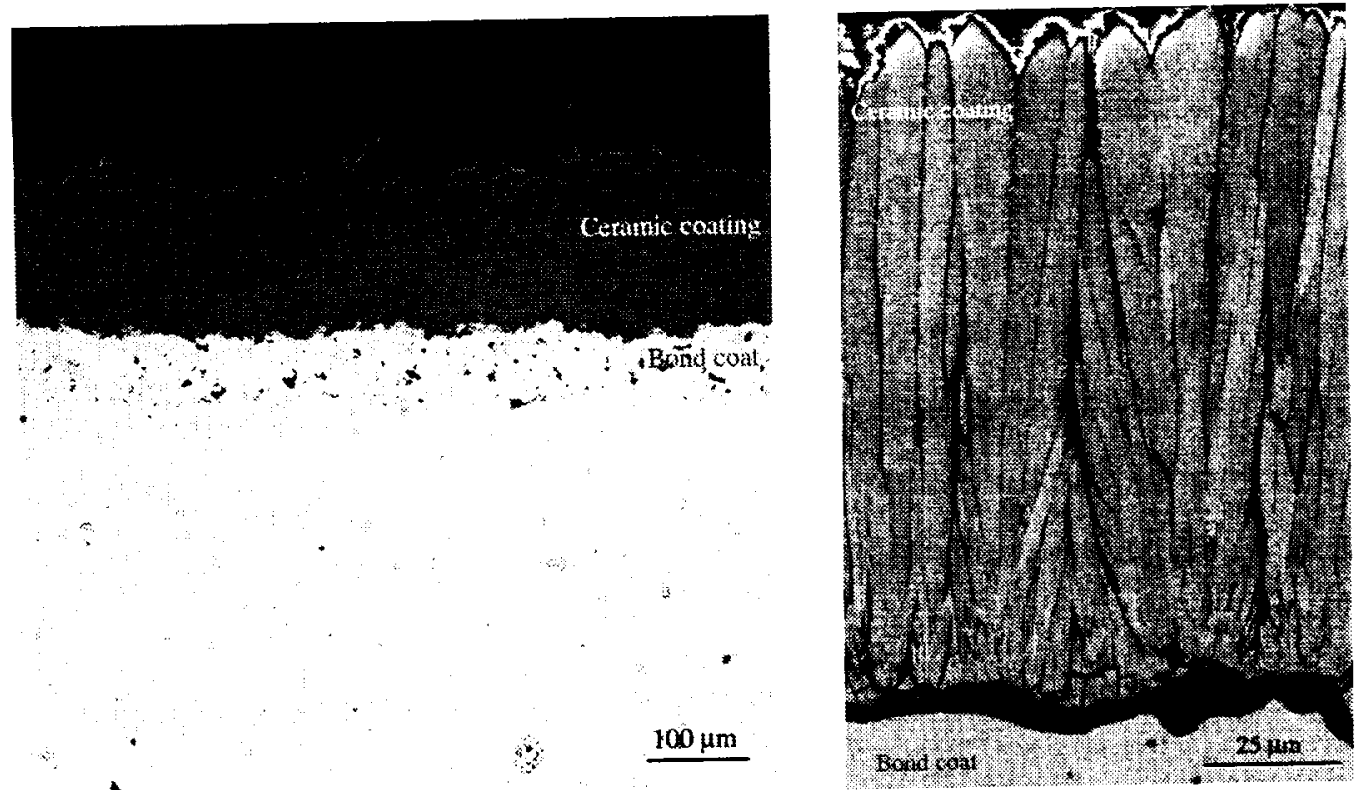

(a)

(b)

Fig. 1 Microstructures of typical TBC systems on a superalloy substrate. (a) Plasma-sprayed thermal barrier coating; (b) EB-PVD thermal barrier coating.

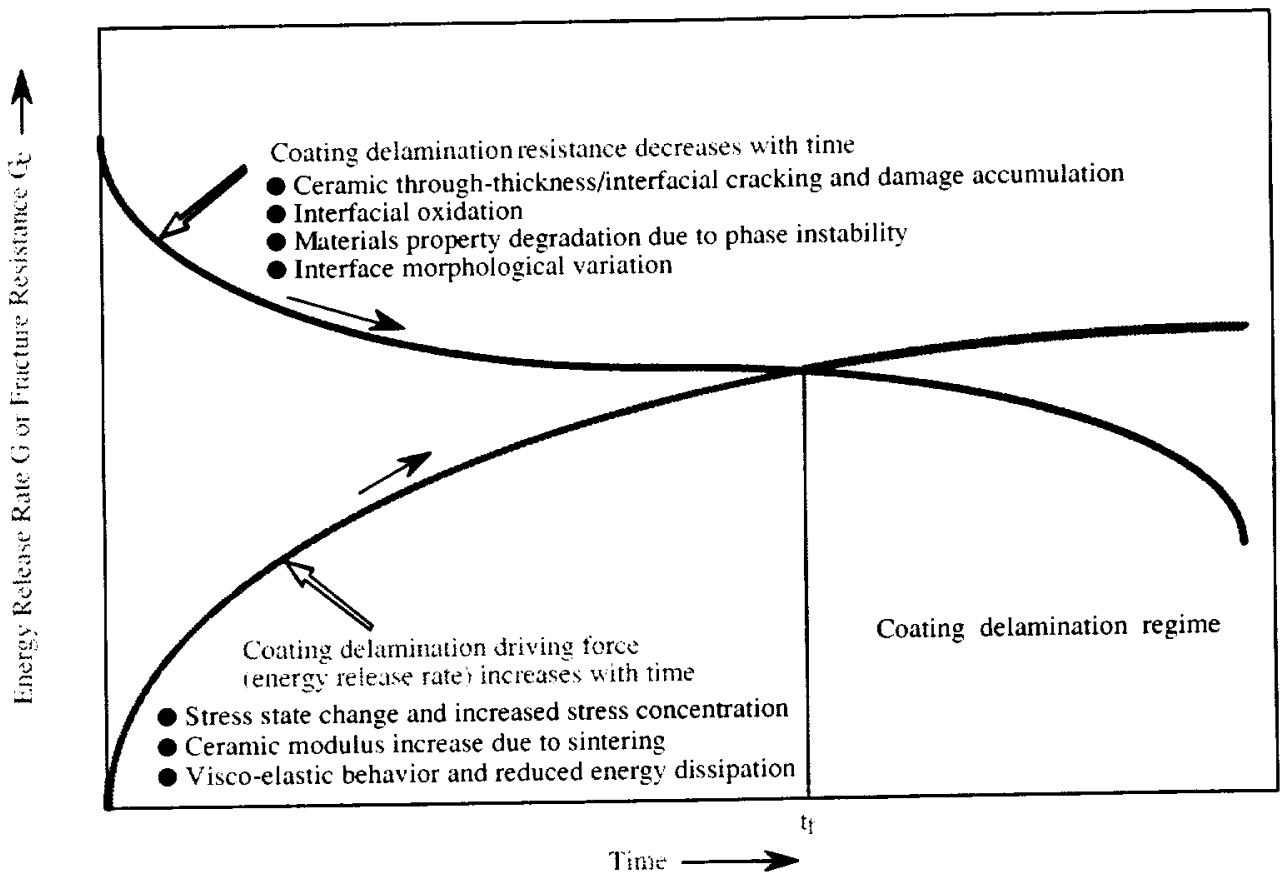

Fig. 2 Life prediction of TBC systems: a dynamic approach for the dynamic systems. The coating life $t_{f}$ is determined by coating delamination driving force and resistance [1]. 
The purpose of this paper is to describe thermophysical and thermomechanical properties of the ceramic coatings which affect the coating failure driving force and resistance. Experimental testing techniques have been

developed to characterize ceramic coating properties and to investigate coating failure mechanisms. Critical issues such as ceramic sintering, creep, and thermal fatigue are discussed. Emphasis is placed on the dynamic changes in the coating thermal conductivity and elastic modulus, fatigue and creep interactions, and resulting failure mechanisms during the simulated engine tests.

\section{SINTERING AND CREEP OF CERAMIC THERMAL BARRIER COATINGS}

Ceramic coating sintering and creep at high temperature are among the most important issues for the development of advanced thermal barrier coatings. It has been recognized that high temperature coating sintering and creep effects are profound and detrimental to coating performance [2-9]. Not only can sintering and creep result in considerable coating thermal conductivity and elastic modulus increases, but also can cause coating shrinkage cracking and spallation.

The sintering and creep mechanisms of the porous, microcracked ceramic thermal barrier coatings are complex. The densification and deformation cxcurring in TBCs at temperature involve thermally- and stress-activated diffusion. and mechanical compaction processes $[8,9]$. The ceramic coatings creep has been observed under mechanical compressive and tensile loads at room temperature [10-12]. At higher stress and temperature levels, the ceramic sintering and creep rates can be further increased. The stress and temperature dependence of the ceramic creep rate has been reported for typical plasma-sprayed coating systems $[8,9,12-15]$. Faster initial sintering and creep rates are often observed for the plasma-sprayed coatings. This phenomenon can be explained by the 
predominant splat sliding and microcrack sintering during the initial-stage sintering and creep processes.

For the EB-PVD thermal barrier coatings, high porosity is present in the in-plane directions between the columnar grains. Intra-columnar micropores also exist after the deposition process. Significant in-plane sintering and creep strains in EB-PVD coatings have been observed under high heat flux/high temperature conditions using the laser sintering-creep technique [16]. Sintering of the EBPVD coatings under the high heat flux conditions was demonstrated as "welding" of the loose individual columnar grains, and thus generated surface wedge-shape cracks in the coatings. The long-term thermal conductivity increase observed was probably due to the sintering of the intra-columnar micropores.

\section{THERMAL CONDUCTIVITY OF THERMAL BARRIER COATINGS}

Low thermal conductivity is one of the most critical requirements for thermal barrier coatings. The current $\mathrm{ZrO}_{2}-8 \mathrm{wt} \% \mathrm{Y}_{2} \mathrm{O}_{3}$ coating material has low intrinsic thermal conductivity (about $2.5 \mathrm{~W} / \mathrm{m}-\mathrm{K}$ ), and further conductivity decrease can be achieved by micropores and microcracks within the coating. A typical plasma-sprayed $\mathrm{ZrO}_{2}-8 \mathrm{wt} \% \mathrm{Y}_{2} \mathrm{O}_{3}$ coating has an initial thermal conductivity value of about $1 \mathrm{~W} / \mathrm{m}-\mathrm{K}$ [17]. However, ceramic sintering can significantly increase the TBC thermal conductivity.

A steady-state laser heat flux technique has been developed to determine the temperature-dependent change kinetics of the coating thermal conductivity necessary for coating design and life prediction. The test facility enables the measurement of critical TBC thermal conductivity data under the temperature and thermal gradients that are realistically expected to be encountered in advanced engine systems $[18,19]$. A schematic diagram showing the laser thermal 
conductivity rig is given in Figure 3. This test rig consists of a $3.0-\mathrm{kW} \mathrm{CO} 2$ continuous-wave laser (wavelength of $10.6 \mu \mathrm{m}$ ), a motor-driven rotating test station, and temperature measurement instrumentation, such as thermography and infrared pyrometry. The laser surface heating and the backside air cooling allow establishing appropriate steady-state temperature gradients across the coating systems. An integrating $\mathrm{ZnSe}$ lens combined with the specimen rotation ensures a uniform laser power distribution for the specimen heating. Overall thermal conductivity changes can, thus, be continuously monitored in real time by carefully measuring the temperature difference across the ceramic coating.

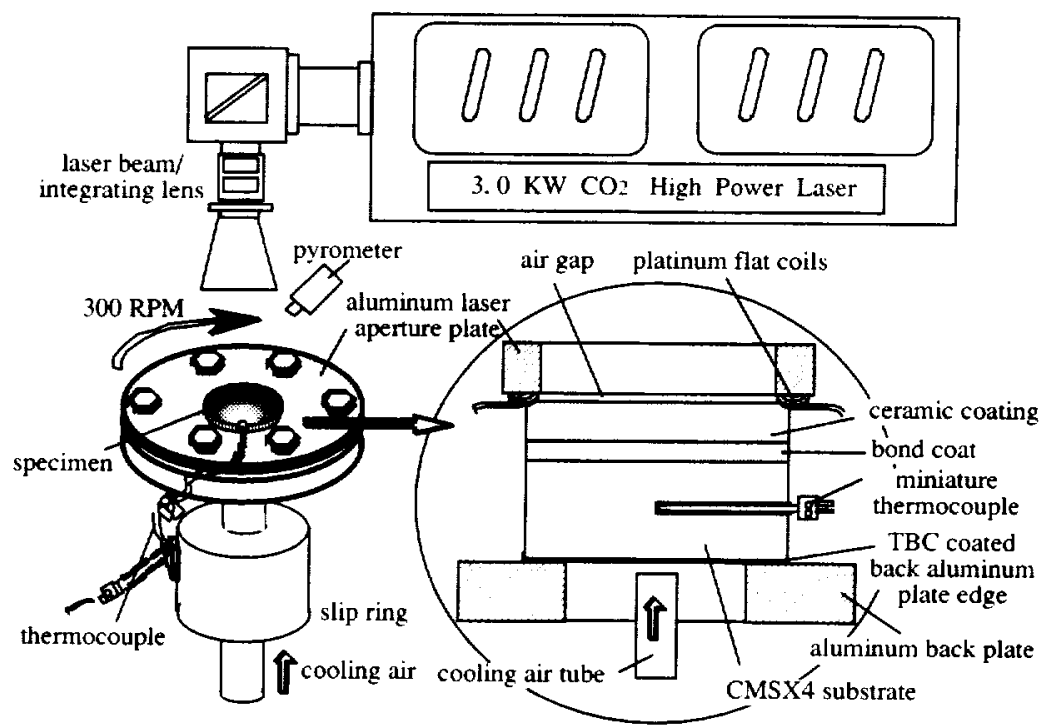

Fig. 3 Laser high heat flux rig for determining thermal conductivity change kinetics of thermal barrier coatings. During the test, the ceramic surface and the metal backside temperatures are measured by infrared pyrometers. The metal substrate mid-point temperature can be obtained by an embedded miniature type-K thermocouple. The interfacial temperatures, and the actual heat flux passing through the thermal barrier coating system, are therefore determined under the steady-state laser heating conditions by a one-dimensional (one-D) heat transfer model [18]. 
Temperature-dependent coating thermal conductivity kinetics of a $254 \mu m$-thick $\mathrm{ZrO}_{2}-\mathrm{Y}_{2} \mathrm{O}_{3}$ thermal barrier coating, determined by the steady-state laser heat flux testing under a fixed heat flux $\left(64 \mathrm{~W} / \mathrm{cm}^{2}\right)$, are illustrated in Figure 4. Because a thermal conductivity gradient is expected across the ceramic coating under the high thermal gradient conditions (due to the more rapid thermal conductivity increase near the ceramic surface as compared to near the ceramic/bond coat interface), the observed ceramic thermal conductivity increase reflects an overall effect of the conductivity change in the coating. The coating shows faster initial conductivity increases, presumably due to the fast microcrack sintering rate at the initial stage. After long-term testing, the conductivity seems to reach saturation conductivity values that are dependent on the testing temperatures. The experimental coating thermal conductivity change kinetics for the $\mathrm{ZrO}_{2}-8 \mathrm{wt} \% \mathrm{Y}_{2} \mathrm{O}_{3}$ can be expressed as

$$
\begin{gathered}
\frac{k_{c}-k_{c}^{0}}{k_{c}^{\text {inf }}-k_{c}^{0}}=102.2 \cdot \exp \left(-\frac{68228}{R T}\right)\left\{1-\exp \left[-\frac{t}{\tau}\right]\right\} \\
\tau=572.5 \cdot \exp \left(\frac{41710}{R T}\right)
\end{gathered}
$$

where $k_{c}$ is the coating thermal conductivity at any given time t, $k_{c}^{0}$ and $k_{c}^{\text {inf }}$ are ceramic coating thermal conductivity values at the initial time and at infinitely long time, respectively, $R$ is gas constant, and $\tau$ is relaxation time. 


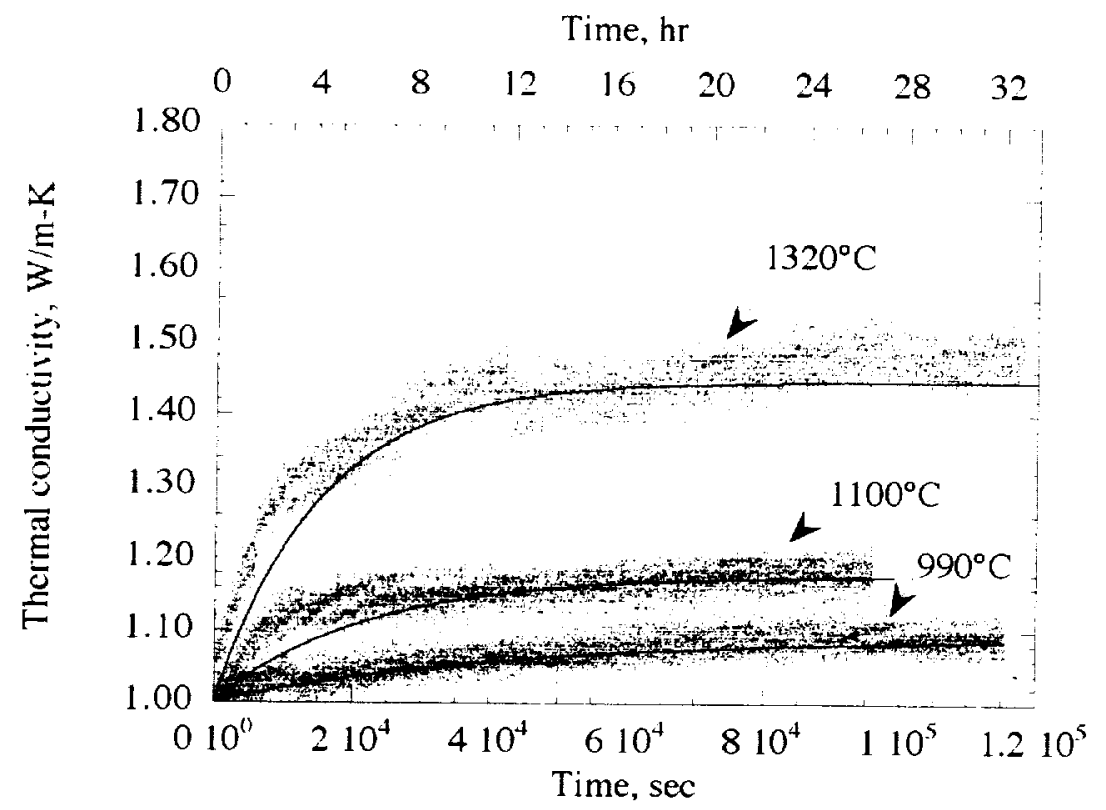

Fig. 4 Overall thermal conductivity change kinetics of the $\mathrm{ZrO}_{2}-8 w t \% \mathrm{Y}_{2} \mathrm{O}_{3}$ thermal barrier coating determined by the real-time laser heat flux testing at surface test temperatures of $990^{\circ} \mathrm{C}, 1100^{\circ} \mathrm{C}$ and $1320^{\circ} \mathrm{C}$ (heat flux $64 \mathrm{~W} / \mathrm{cm}^{2}$ ).

From the temperature dependence of the thermal conductivity change kinetics, the thermal conductivity gradients in the TBC coatings as a function of time can be derived. Typical thermal conductivity distributions in a $\mathrm{ZrO}_{2}-$ $8 \mathrm{wt} \% \mathrm{Y}_{2} \mathrm{O}_{3}$ thermal barrier coating are shown in Figure 5. It can be seen that the conductivity increase near the surface is more significant than that near the interface under the thermal gradient testing conditions. For a given time, a lower interface temperature will result in a lower measured average conductivity value of the coating system, but the differences beween them are relatively small. Therefore, it is advantagous from coating durability and measurement accuracy point of view to investigate the ceramic coating thermal conductivities at higher heat fluxes and lower interface temperatures. 


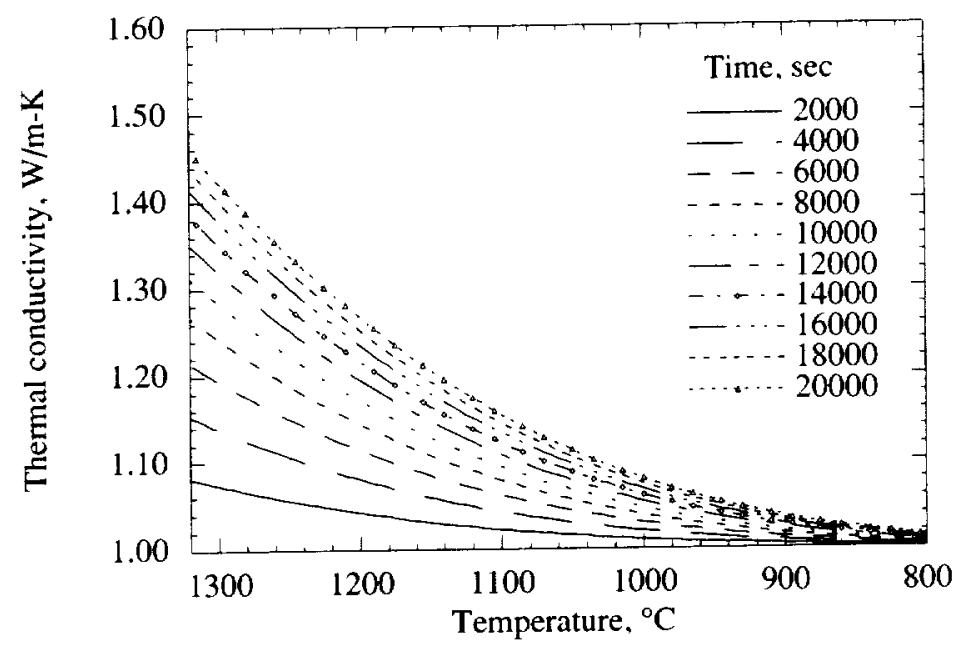

(a)

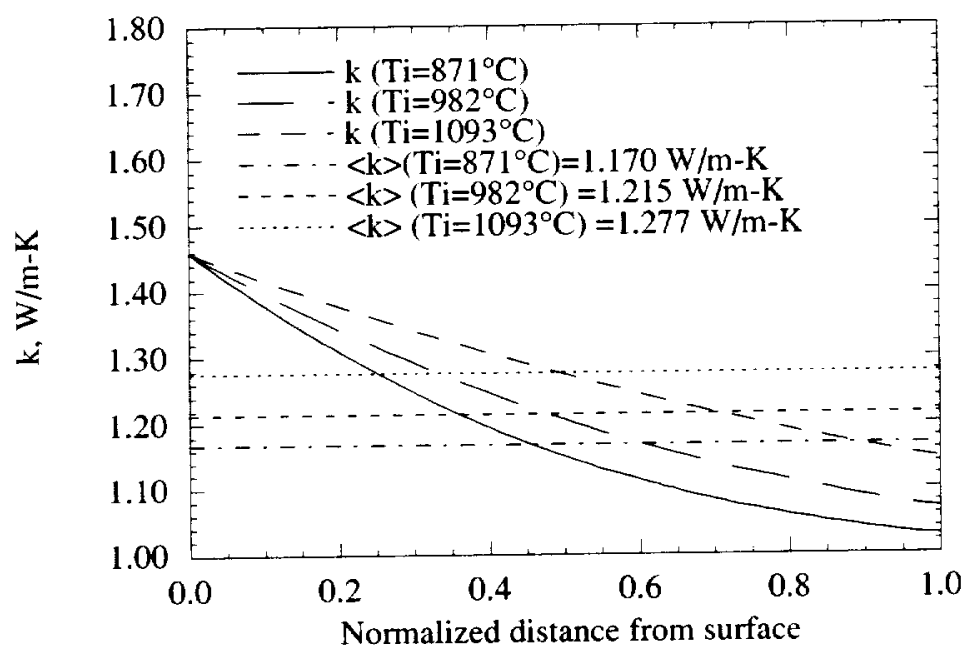

(b)

Fig. 5 Thermal conductivity distributions in a $\mathrm{ZrO}_{2}-8 w t \% \mathrm{Y}_{2} \mathrm{O}_{3}$ thermal barrier coating. (a) The ceramic thermal conductivity as a function of temperature and time; (b) Thermal conductivity gradients and corresponding average thermal conductivity values $\langle\mathrm{k}\rangle$ in the ceramic coating tested at three different interface temperatures after 20000 seconds (surface temperature $\mathrm{T}_{\mathrm{s}}=1315.5^{\circ} \mathrm{C}$; interface temperatures $\mathrm{T}_{\mathrm{i}}$ are $871^{\circ} \mathrm{C}, 982^{\circ} \mathrm{C}$ and $1093^{\circ} \mathrm{C}$, respectively) 


\section{ELASTIC MODULUS OF THERMAL BARRIER COATINGS}

Elastic modulus of the porous ceramic coatings is an important coating property parameter. The stress states in the ceramic coating are directly related to the coating modulus. The coating spallation resistance is thus also greatly affected by the coating modulus.

The as-sprayed coating modulus is relatively low due to its high porosity. Hysteresis in the loading-unloading curves was observed due to interactions between the microcracks and micro-pores [11]. The initial compressive modulus values were within the range of 34 to $64 \mathrm{GPa}$ for a plasma-sprayed $\mathrm{ZrO}_{2}$ $8 \mathrm{wt} \% \mathrm{Y}_{2} \mathrm{O}_{3}$ coating in the low stress-strain region [11]. In the higher stress-strain region, coating modulus increased to about $100-120 \mathrm{GPa}$ probably because the majority of the microcrack surfaces are in contact, resulting in the increased coating stiffness. The overall coating modulus also increases with the number of compressive cycles at room temperature, at least partially due to a permanent compaction process.

At higher temperature, the elastic modulus of the porous ceramic coating will increase significantly because of the sintering densification process $[9,18]$. The modulus increase rate will depend upon the actual temperatures and stresses that the coating experiences. Under the high heat flux conditions, however, a significant elastic modulus gradient will develop and evolve with time. Laser simulated heat flux testing demonstrated that the ceramic coating micro-porosity decreased with increasing laser test time [9]. The porosity gradients across the coating thickness after laser testing were noted and correlated to the measured total creep strain gradients. The elastic modulus change kinetics, determined by the micro-indentation technique across the coating system are shown in Figure 6. The experimental data can be described by the following relation 


$$
\frac{E_{c}-E_{c}^{0}}{E_{c}^{\text {inf }}-E_{c}^{0}}=C_{E}\left\{1-\exp \left[-\frac{t}{\tau}\right]\right\}
$$

where $E_{c}$ is the coating modulus at any given time $\mathrm{t}, E_{c}^{0}$ and $E_{c}^{\mathrm{inf}}$ are ceramic coating modulus values at the initial time and at infinitely long time, respectively, $\tau$ is relaxation time, $C_{E}$ is a constant related to temperature and stress in the coating system. It can be seen that a modulus gradient was established in the ceramic coating that evolved with time under the laser imposed temperature and stress gradients. The surface showed a very fast increase in the modulus change kinetics. The surface of the ceramic coating reached nearly the assumed final modulus value of $125 \mathrm{GPa}$ in about 20 hours, from an initial modulus of $70 \mathrm{GPa}$. However, a longer time is required for the inner layers of the ceramic coating to obtain the final modulus value by laser sintering due to the lower temperatures and stresses under the thermal gradient test conditions.

\section{THERMAL FATIGUE AND CREEP INTERACTIONS OF THERMAL BARRIER COATINGS}

Thermal barrier coating systems experience severe thermal fatigue during service. The thermal fatigue results from the cyclic thermal stresses due to the thermal cycling and/or thermal transients encountered in an engine.

Under operating heat flux conditions, the coating modulus will increase with time due to the coating sintering and densification process, thus resulting in coating stress increase with time. The thermal elastic stress generated can also relax with increased creep strains. Figure 7 shows the modeled coating elastic

stress evolution as a function of time and coating depth across a thick TBC system tested under a high thermal gradient that places essentially the entire coating in 
compression. It can be seen that the coating compressive stresses in the inner layers increase with time initially, then maintain approximately constant values for longer times. The stress variation is consistent with the modulus change in the coating for this region. However, the coating stresses in the outer layers first reach maximum values, then decrease significantly with increasing time because considerable stress relaxation occurs due to the coating creep. Significant creep shrinkage strain gradients are generated and observed in the ceramic coating systems [9].

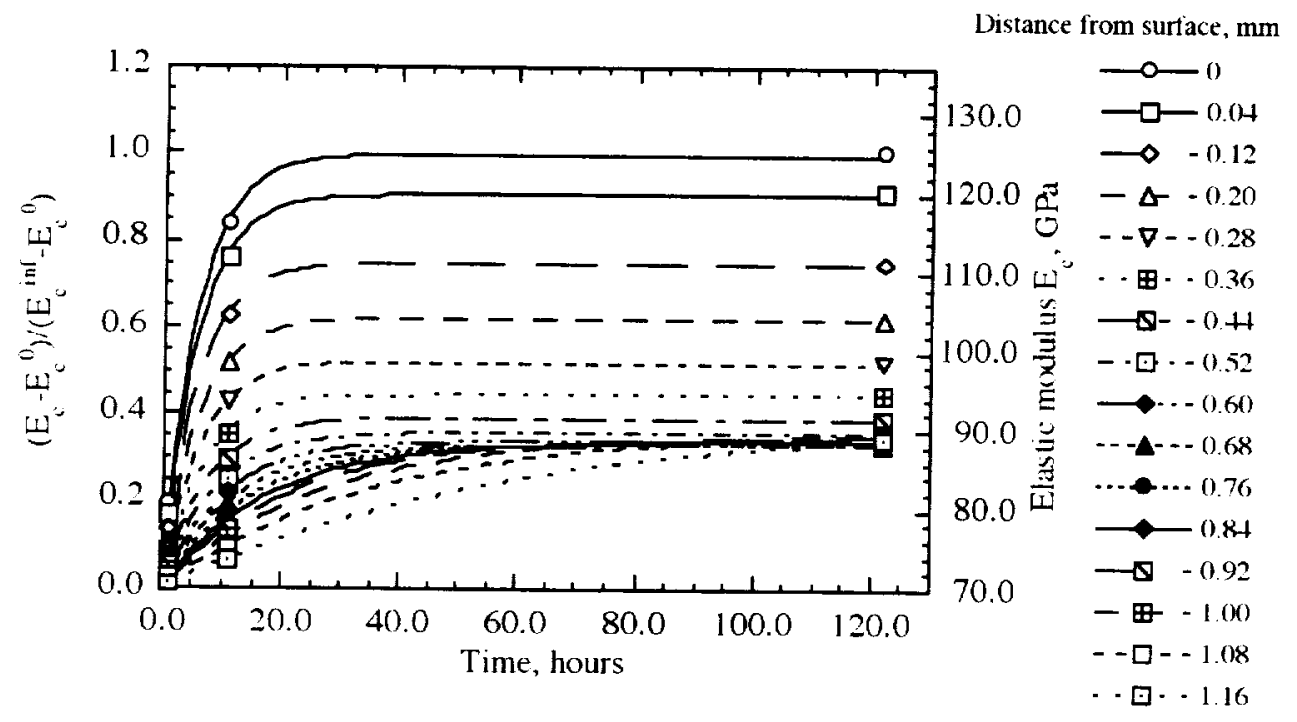

Fig. 6 Elastic modulus evolution in a $\mathrm{ZrO}_{2}-\mathrm{Y}_{2} \mathrm{O}_{3}$ thermal barrier coating under laser heat flux sintering and creep conditions [18].

Thermal fatigue behavior of thick thermal barrier coatings was investigated under simulated diesel engine thermal transients $[20,21]$. The sintering and creep strains in the ceramic coating under high temperature thermal gradient conditions will lead to a tensile stress state during cooling, thus providing the major driving force for the vertical crack growth under low cycle fatigue (LCF) conditions. Figure 8 shows a typical surface vertical crack propagation near 
the ceramic/bond coat interface, and initiating the coating delamination. The increased fatigue crack growth rate in the ceramic coating was experimentally observed using longer heating cycles or higher test temperatures [21]. The experiments demonstrate the strong interactions between sintering, creep and thermal fatigue of the ceramic coating.

For thin plasma-sprayed and EB-PVD thermal barrier coatings, sintering and creep can also significantly increase the coating spallation driving force by increasing the coating modulus and accumulated creep strains. Coating buckling and spallation failures have been observed both at high temperatures, and after cooling and subsequent reheating $[1,16]$. Figure 9 shows the accelerated ceramic coating delamination and buckling in a TBC coated single crystal superalloy system. The accelerated failure is due to the reduced interfacial adhesion from bond coat oxidation after 35 hour laser high heat flux testing, with a subsequent laser reheating cycle.
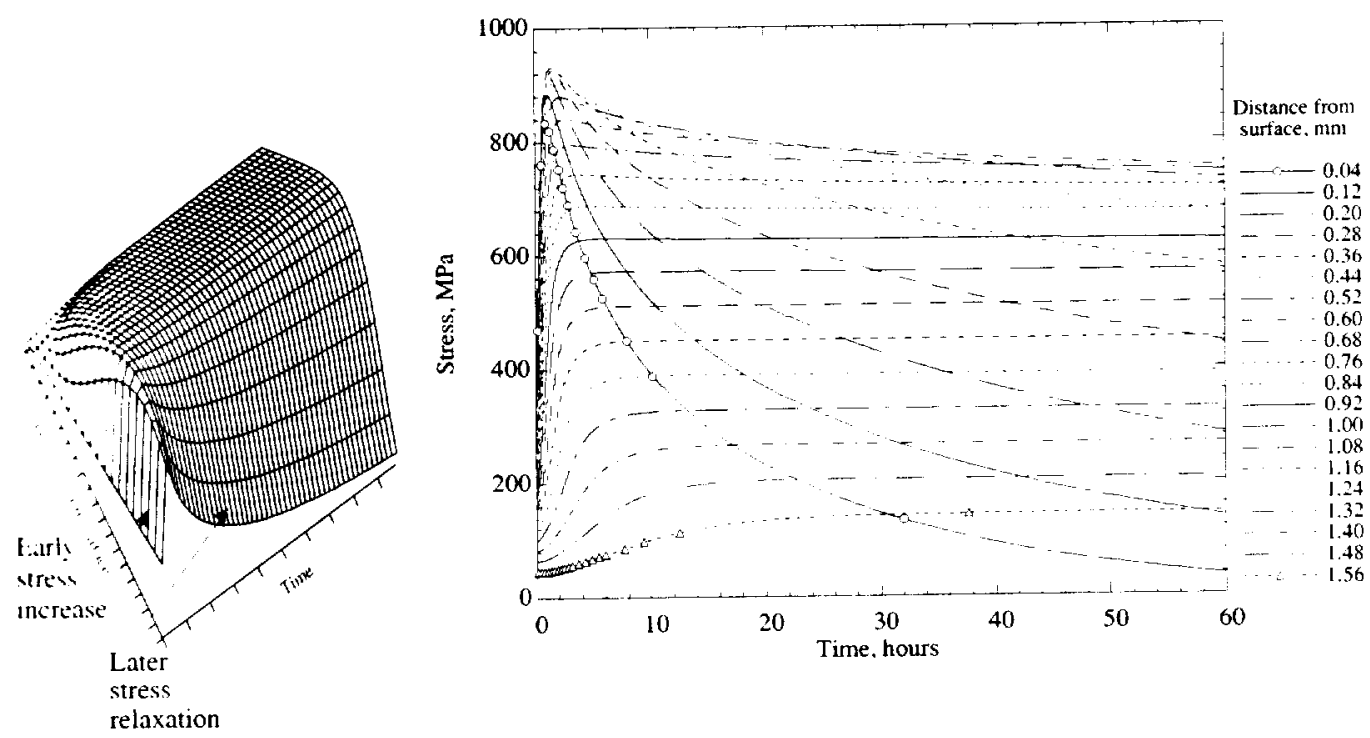

Fig. 7 Modeled in-plane coating compressive stresses as a function of time and coating depth for a thick thermal barrier coating under large temperature gradient testing. 


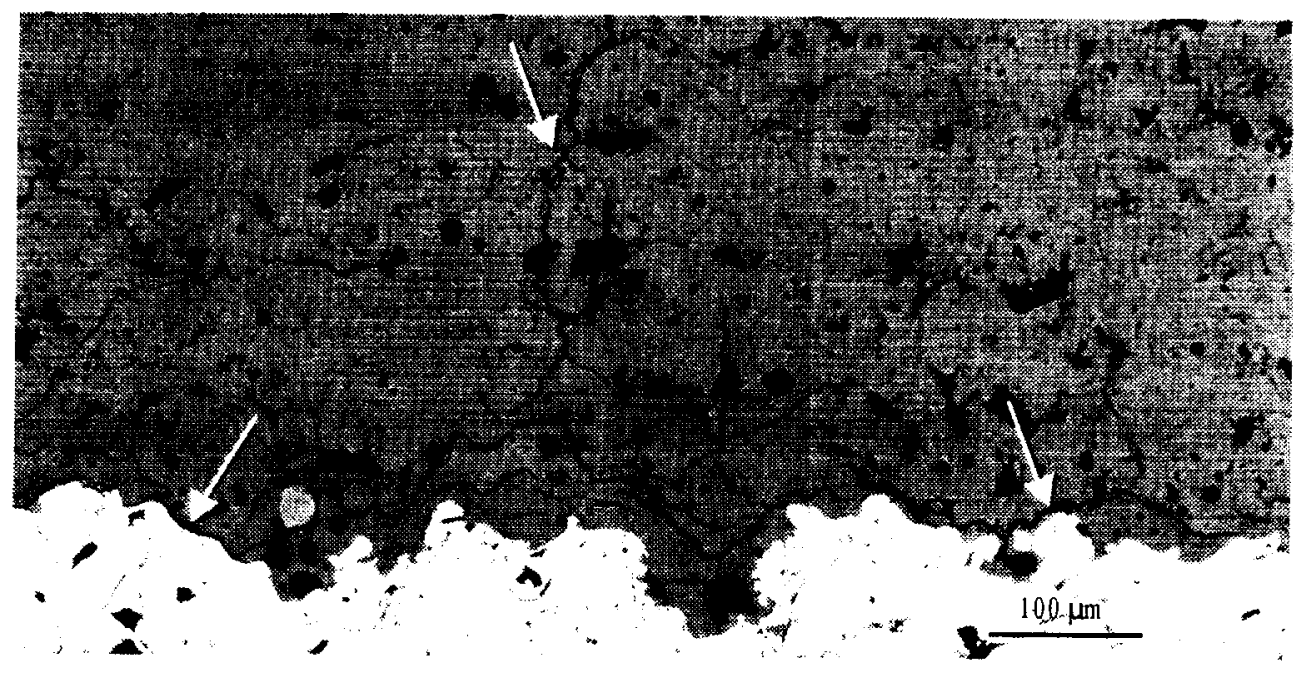

Fig. 8 A surface vertical crack propagation and coating delamination under the laser heat flux induced thermal fatigue loads (arrows indicating the crack paths).
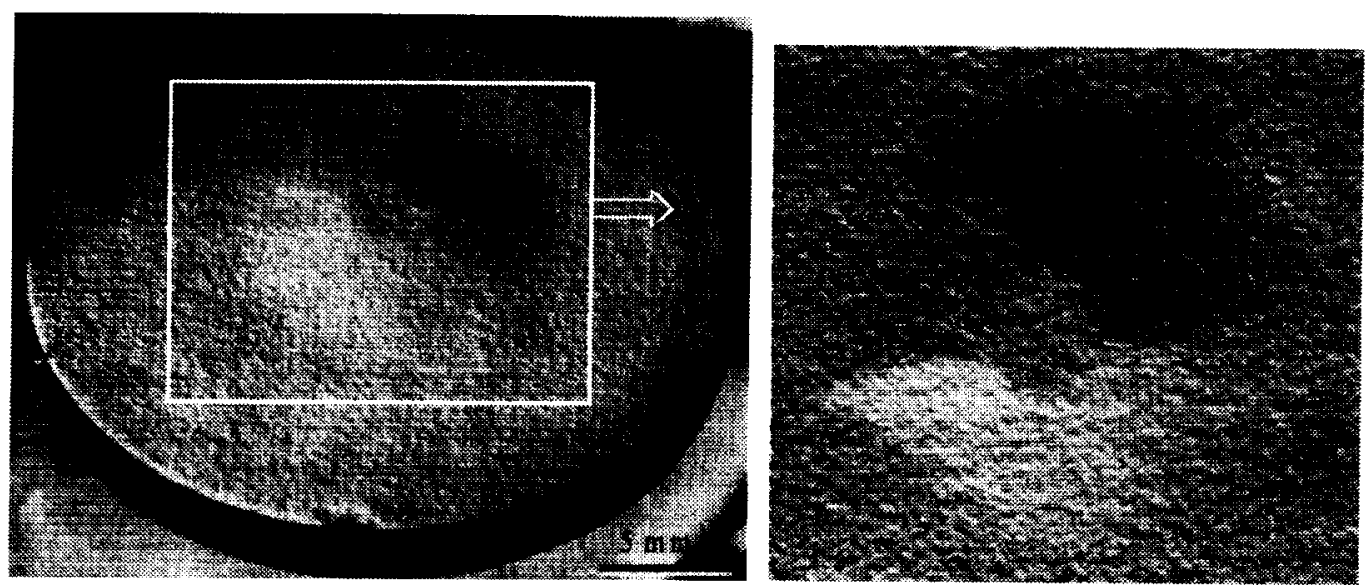

Fig. 9 The substantial ceramic coating delamination and buckling in a $\mathrm{ZrO}_{2}-$ $8 \mathrm{wt} \% \mathrm{Y}_{2} \mathrm{O}_{3} / \mathrm{NiCrAlY}$ bond coat/CMSX-4 substrate system generated after 35 hour laser high heat flux testing, and a second time laser reheating (interface temperature approximately $1100^{\circ} \mathrm{C}$ ). 


\section{CONCLUDING REMARKS}

This paper describes important thermal barrier coating design and life prediction issues such as ceramic sintering and creep, thermal conductivity and elastic modulus change kinetics, bond coat oxidation and the ceramic coating thermal fatigue. Experimental techniques have been developed to characterize important thermo-physical and thermo-mechanical properties of thermal barrier coating systems under near-realistic engine conditions. The property data will provide helpful insight into the coating failure processes and support mechanismand thermal fatigue-based coating life prediction models.

\section{REFERENCES}

[1] D. Zhu and R. A. Miller, "Thermal Barrier Coatings for Advanced Gas Turbine and Diesel Engines," NASA Glenn Research Center, Cleveland, Ohio, NASA TM-209453, October 1999.

[2] R. F. Firestone, W. R. Logan, and J. W. Adams, "Creep of Plasma Sprayed Zirconia," NASA Lewis Research Center, Cleveland, Ohio, NASA CR$167868,1982$.

[3] H. E. Eaton and R. C. Novak, "Sintering Studies of Plasma-Sprayed Zirconia," Surface and Coatings Technology, vol. 32, pp. 227-236, 1987.

[4] S. M. Meier, D. M. Nissley, and K. D. Sheffler, "Thermal Barrier Coating Life Prediction Model Development: Phase II-Final Report," NASA Lewis Research Center, Cleveland, Ohio, NASA CR-182230, 1991.

[5] H. E. Eaton, J. R. Linsey, and R. B. Dinwiddie, "The Effect of Thermal Aging on the Thermal Conductivity of Plasma Sprayed Fully Stabilized Zirconia," in Thermal Conductivity, vol. 22, T. W. Tong, Ed.: Technomic Publishing Co., Inc., Lancaster, Pennsylvania, 1994, pp. 289-300. 
[6] J. G. Goedjen, W. J. Brindley, and R. A. Miller, "Sintering of PlasmaSprayed Sol gel Zirconia-Yttria as a Function of Silica Content," in Advances in Thermal Spray Science and Technology, C. C. Berndt and S. Sampath, Eds.: ASM International, Materials Park, Ohio, 1995, pp. 73-77.

[7] D. Zhu and R. A. Miller, "Investigation of Thermal Fatigue Behavior of Thermal Barrier Coating Systems," Surface and Coatings Technology, vol. 94-95, pp. 94-101, 1997.

[8] D. Zhu and R. A. Miller, "Sintering and Creep Behavior of PlasmaSprayed Zirconia and Hafnia-Based Thermal Barrier Coatings," Surface and Coatings Technology, vol. 108-109, pp. 114-120, 1998.

[9] D. Zhu and R. A. Miller, "Determination of Creep Behavior of Thermal Barrier Coatings under Laser Imposed High Thermal and Stress Gradient Conditions," Journal of Materials Research, vol. 14, pp. 146-161, 1999.

[10] T. A. Cruse, B. P. Johnsen, and A. Nagy, "Mechanical Properties Testing and Results for Thermal Barrier Coatings," Journal of Thermal Spray Technology, vol. 6, pp. 57-66, 1997.

111] S. R. Choi, D. Zhu, and R. A. Miller, "High-Temperature Slow Crack Growth, Fracture Toughness and Room-Temperature Deformation Behavior of Plasma-Sprayed $\mathrm{ZrO}_{2}-8 \mathrm{wt} \% \mathrm{Y}_{2} \mathrm{O}_{3}$," Ceramic Eng. Sci. Proc., vol. 19, pp. 293-301, 1998.

1121 S. R. Choi, D. Zhu, and R. A. Miller, "Flexural and Compressive Strength, and Room-Temperature Creep/Relaxation Properties of Plasma-Sprayed $\mathrm{ZrO}_{2}-8 \mathrm{wt} \% \mathrm{Y}_{2} \mathrm{O}_{3}$," Ceram. Eng. Sci. Proc., vol. 20, pp. 365-372, 1999.

113] G. Thum, G. A. Schneider, and F. Aldingger, "High Temperature Deformation of Plasma-Sprayed $\mathrm{ZrO}_{2}$-Thermal Barrier Coatings," Mater. Sci. Eng., vol. A233, pp. 176, 1997.

[14] E. F. Rejda, D. F. Socie, and B. Beardsley, "Fatigue Behavior of A Plasma-Sprayed $8 \% \mathrm{Y}_{2} \mathrm{O}_{3}-\mathrm{ZrO}_{2}$ Thermal Barrier Coating," Fatigue Fract. Eng. Mater. Struct., vol. 20, pp. 1043-1050, 1997. 
[15] E. F. Rejda, D. F. Socie, and T. Itoh, "Deformation Behavior of PlasmaSprayed Thick Thermal Barrier Coatings," Surface and Coatings Technology, vol. 113, pp. 218-226, 1999.

[16] D. Zhu, R. A. Miller, and B. A. Nagaraj, "Thermal Conductivity of EBPVD Thermal Barrier Coatings Evaluated by the Steady-State Laser Heat Flux Technique," presented at International Conference on Metallurgical Coatings and Thin Films, San Diego, 2000.

[17] R. A. Miller and G. W. Leissler, "Characterization and Durability Testing of Plasma-Sprayed Zirconia-Yttria and Hafnia-Yttria Thermal Barrier Coatings," NASA Lewis Research Center, Cleveland, Ohio, NASA TP3296, March 1993.

[18] D. Zhu and R. A. Miller, "Thermal Conductivity and Elastic Modulus Evolution of Thermal Barrier Coatings Under High Heat Flux Conditions," NASA Glenn Research Center, Cleveland, Ohio, NASA TM$209069,1999$.

[19] D. Zhu and R. A. Miller, "Thermal Conductivity Change Kinetics of Ceramic Thermal Barrier Coatings Determined by the Steady-State Laser Heat Flux Technique," NASA Glenn Research Center, Cleveland, Ohio, Research and Technology, 1999.

[20] D. Zhu and R. A. Miller, "Influence of High Cycle Thermal Loads on Thermal Fatigue Behavior of Thick Thermal Barrier Coatings," NASA Lewis Research Center, Cleveland, Ohio, NASA TP-3676, 1997.

[21] D. Zhu and R. A. Miller, "Investigation of Thermal High Cycle and Low Cycle Fatigue Mechanisms of Thick Thermal Barrier Coatings," Materials Science and Engineering, vol. A245, pp. 212-223, 1998. 
Public reporting burden for this collection of information is estimated to average 1 hour per response, including the time for reviewing instructions, searching existing data sources, gathering and maintaining the data needed, and completing and reviewing the collection of information. Send comments regarding this burden estimate or any other aspect of this Davis Highway, Suite 1204, Artington. VA tons for reducing this burden, to Washington Headquarters Services. Directorate for Information Operations and Reports, 1215 Jefferson Davis Highway, Suite 1204, Artington, VA 22202-4302, and to the Otfice of Management and Budget, Paperwork Reduction Project (0704-0188), Washington, DC 20503.

\begin{tabular}{l|l|l}
\hline 1. AGENCY USE ONLY (Leave blank) & 2. REPORT DATE & 3. REPORT TYPE AND DATES COVERED
\end{tabular}

4. TITLE AND SUBTITLE July 2000

Technical Memorandum

Thermophysical and Thermomechanical Properties of Thermal Barrier

Coating Systems

6. AUTHOR(S)

Dongming Zhu and Robert A. Miller

National Aeronautics and Space Administration

John H. Glenn Research Center at Lewis Field

Cleveland, Ohio 44135-3191

WU-714-04-20-00

9. SPONSORINGMONITORING AGENCY NAME(S) AND ADDRESS(ES)

National Aeronautics and Space Administration

Washington, DC 20546-0001

8. PERFORMING ORGANIZATION REPORT NUMBER

E-12356

10. SPONSORING/MONITORING AGENCY REPORT NUMBER

NASA TM-2000-210237

11. SUPPLEMENTARY NOTES

Prepared for the 24th Annual Cocoa Beach Conference and Exposition, International Conference on Engineering Ceramics and Structures sponsored by the American Ceramic Society, Cocoa Beach, Florida, January 23-28, 2000. Dongming Zhu, Ohio Aerospace Institute 22800 Cedar Point Road, Brook Park, Ohio 44142; Robert A. Miller, NASA Glenn Research Center. Responsible person, Dongming Zhu, organization code 5160, (216) 433-5422.

12a. DISTRIBUTION/AVAILABILITY STATEMENT

Unclassified - Unlimited

Subject Categories: 24 and 25

Distribution: Nonstandard

This publication is available from the NASA Center for AeroSpace Information, (301) 621-0390.

13. ABSTRACT (Maximum 200 words)

Thermal barrier coatings have been developed for advanced gas turbine and diesel engine applications to improve engine reliability and fuel efficiency. However, the issue of coating durability under high temperature cyclic conditions is still of major concern. The coating failure is closely related to thermal stresses and oxidation in the coating systems. Coating shrinkage cracking resulting from ceramic sintering and creep at high temperatures can further accelerate the coating failure process. The purpose of this paper is to address critical issues such as ceramic sintering and creep, thermal fatigue and their relevance to coating life prediction. Novel test approaches have been established to obtain critical thermophysical and thermomechanical properties of the coating systems under near-realistic temperature and stress gradients encountered in advanced engine systems. Emphasis is placed on the dynamic changes of the coating thermal conductivity and elastic modulus, fatigue and creep interactions, and resulting failure mechanisms during the simulated engine tests. Detailed experimental and modeling results describing processes occurring in the thermal barrier coating systems provide a framework for developing strategies to manage ceramic coating architecture, microstructure and properties.

\section{SUBJECT TERMS}

Thermal barrier coatings; Life predictions; Thermal conductivity;

Thermal gradient testing: Stress evolution
17. SECURITY CLASSIFICATION OF REPORT
Unclassified

18. SECUAITY CLASSIFICATION
OF THIS PAGE
Unclassified
Unclassified

NSN 7540-01-280-5500
19. SECURITY CLASSIFICATION OF ABSTRACT Unclassified
15. NUMBER OF PAGES 23

16. PRICE CODE

A03

20. LIMITATION OF ABSTRACT 
